\title{
A INDÚSTRIA DA INSEGURANÇA E A VENDA DA SEGURANÇA ${ }^{1}$
}

\author{
Estela Scheinvar ${ }^{2}$ \\ Universidade do Estado do Rio de Janeiro, Rio de Janeiro-RJ, Brasil \\ Universidade Federal Fluminense, Niterói-RJ, Brasil
}

\begin{abstract}
RESUMO. Nos chamados tempos modernos a lei é um elemento fundamental à organização social, articulada pela produção do homem livre, do cidadão, governado por dispositivos de disciplina e segurança. Para fazê-los funcionar, liberdade e controle são noções centrais, fundamentos da segurança, cuja existência apenas é possível se produzida a insegurança. Uma relação segundo a qual a insegurança convoca a segurança e esta a justiça com os aparelhos que lhe subsidiam. A partir das análises propostas por Michel Foucault constata-se que a judicialização é uma perspectiva que incentiva a insegurança para vender segurança como condição para o controle no mundo do capital: alimenta-se uma indústria de insegurança e um espaço de lucro. Relações cotidianas permitem pensar a produção da insegurança como estratégia financeira e de controle biopolítico, acionada por um amplo exército composto inclusive pela universidade, e um mercado de venda de segurança, que vai do incentivo ao medo às vias de fato das armas.
\end{abstract}

Palavras-chave: Segurança; controle social; Foucault, M.

\section{THE INDUSTRY OF INSECURITY AND THE SALE OF SECURITY}

\begin{abstract}
In so-called modern times, the law is a fundamental element for social organization, articulated by the production of the free man, the citizen, governed by devices of discipline and security, which existence is just possible if produced the insecurity. A relationship according to which the insecurity calls the security and this one the justice with its apparatus to subsidize it. From the analysis proposed by Michel Foucault, we can note that the judicialization is a perspective that encourages the insecurity to sell security as a condition for the capitals' world control: it feeds on an industry of insecurity and a profit space. Everyday relationship allow us to think the production of insecurity as a financial and bio political strategy, driven by a large army composed also by the University, and a market to sell security, ranging from the incentive of fear to the blows of weapons.
\end{abstract}

Keywords: Security; social control; Foucault, M.

\section{LA INDUSTRIA DE LA INSEGURIDAD Y LA VENTA DE LA SEGURIDAD}

RESUMEN. En los llamados tiempos modernos la ley es un elemento fundamental para la organización social, articulada por la producción del hombre libre, del ciudadano, gobernado por dispositivos de disciplina y seguridad. Para hacerlos funcionar, libertad y control son nociones centrales, fundamentos de la seguridad, cuya existencia apenas es posible si producida la inseguridad. Una relación según la cual la inseguridad convoca a la seguridad y esta a la justicia con los aparatos que le subsidian. A partir de los análisis propuestos por Michel Foucault constatase que la judicialización es una perspectiva que incentiva la inseguridad para vender seguridad como condición para el control en el mundo del capital: alimentase una industria de inseguridad y un espacio de ganancia. Relaciones cotidianas permiten pensar la producción de la inseguridad como estrategia financiera y de control biopolítico, accionada por un amplio ejército compuesto incluso por la universidad, y un mercado de venta de seguridad, que va del incentivo al miedo a las vías de hecho de las armas.

Palabras-clave: Seguridad; control social; Foucault, M.

1 Apoio e financiamento: Fundação de Amparo à Pesquisa do Estado do Rio de Janeiro (FAPERJ).

2 Endereço para correspondência: Rua São Francisco Xavier, 524 - Pavilhão João Lyra Filho - $12^{\circ}$ Andar - Bloco F Sala 12.111 - Maracanã - CEP 20.550-900 - Rio de Janeiro-RJ, Brasil. E-mail: estelascheinvar@gmail.com. 


\section{DETENHAM A INSEGURANÇA!}

Marco Polo descreve uma ponte, pedra por pedra.

- Mas qual é a pedra que sustenta a ponte? - pergunta Kublai Khan.

- A ponte não é sustentada por esta ou aquela pedra - responde Marco -,

mas pela curva do arco que estas formam.

Kublai Khan permanece em silêncio, refletindo.

Depois acrescenta:

- Por que falar das pedras? Só o arco me interessa.

Polo responde: - Sem pedras o arco não existe.

Ítalo Calvino (1973/1990, p. 79).

A relevância nacional e internacional do tema da segurança tem capitalizado a atenção e a preocupação coletiva, levando-o a ser considerado um dos grandes motes das campanhas eleitorais dos representantes da democracia parlamentar. Longe de considerar a segurança uma condição natural a ser alcançada ou mantida, no mesmo espírito proposto por Calvino na epígrafe deste texto, quando nos convoca a pensar nas pedras que dão sustentação ao arco, este artigo é um convite para pensar a insegurança como uma produção orientada a fundamentar as práticas significadas como de segurança.

Ao ouvir tele e rádio jornal ou ler a imprensa escrita temos certeza que o grande problema do mundo é a chamada violência cotidiana definida por vandalismo, roubo, furto, assassinato, briga, sequestro..., todos por enfrentamentos pessoais: dentistas queimados por não terem bens suficientes para satisfazer os ladrões, assassinato de motoristas que resistem à entrega do veículo, estudantes abordados com armas na saída das universidades perdem seus computadores e aparelhos celulares, sequestros relâmpagos para a retirada de dinheiro em caixas eletrônicos, roubo dos caixas eletrônicos com retro-escavadeiras, brigas conjugais que levam ao esquartejamento dos corpos, entre tantas outras notícias que ocupam a quase totalidade dos noticiários.

Não é uma questão do tempo dispensado pelos meios de comunicação ao que definem como violência ou insegurança, mas do detalhamento de tais informações, ao lado da omissão ou das apressadas e imprecisas comunicações sobre áreas e questões que também compõem a nossa vida e a respeito das quais se produz uma ignorância, como por exemplo nos casos de coação ostensiva e assassinatos no campo, dados do fluxo financeiro em todos os setores que compõem os serviços públicos, jogo da bolsa de valores, conflitos na maior parte dos países do mundo, decisões das corporações financeiras, procedimentos por meio dos quais funcionam os serviços dos que fazemos uso cotidiano, decisões políticas em relação ao patrimônio público, como no caso dos bens naturais, condições de trabalho de todos os setores da produção no Brasil e nos demais países... Ao lado das minúcias das desventuras cotidianas que habitam as delegacias de polícia - fonte de informação direta de muitos dos meios de comunicação - temos dados soltos e esporádicos, flashes poderíamos dizer, da maior parte das demais dimensões que dizem respeito ao nosso mundo e que nos parecem incompreensíveis.

Não se trata de um erro, mas de uma intenção. Em 2012, quando trabalhadores da Universidade do Estado do Rio de Janeiro entraram em greve por cerca de três meses exigindo o cumprimento da lei, raramente encontrávamos uma notícia sobre o movimento, até o momento em que ele ocupou uma das ruas mais caras da cidade e outro em que a polícia foi chamada para dentro do espaço da Universidade e agrediu os estudantes. Sob a mesma perspectiva, no dia seis de junho de 2013, um importante radialista de uma emissora com cobertura nacional noticia e debate, com sua equipe, a agressão perpetrada pela polícia a uma manifestação de professores de uma rede pública de educação por melhores condições de trabalho. Ao mesmo tempo em que se informa que os policiais usaram da força com balas de borracha, afirma-se a necessidade de manter a ordem e de que os professores que compõem o movimento impeçam que vândalos ocupem as suas fileiras. Em ambos os casos o destaque é dado ao que se chama vandalismo, violência, ao medo, à insegurança. Pouco ou nada sabemos da motivação e dos acontecimentos dos movimentos, ou das lógicas que levam à definição dos modos como os diferentes grupos conduzem suas lutas. O chamado à ordem emerge por meio da ameaça da insegurança.

O que é produzido como perigo? Uma manifestação na Universidade e na rua ou as condições de trabalho em uma das instituições 
de educação superior de referência no Brasil e em uma rede de ensino responsável pela garantia do direito à educação básica de milhões de crianças, jovens e adultos? O perigo e com ele a condição de insegurança são produzidos sempre em defesa de uma certa ordem. Como aponta Foucault (2012a, p. 135), "são os perigos que marcam a importância relativa das infrações: grande perigo de uma pedra jogada, pequeno perigo de uma grande infração penal. ... A justiça deve reagir ao perigo real mais ainda do que ao delito estabelecido". Independentemente do delito definido jurídica ou socialmente, o perigo vai além dele e é neste que a relação de segurança se ancora. A produção de uma prática como perigosa justifica a sua condenação. Interessa, nesse sentido, pensar como é definido o perigo, já que esta é uma noção política que dá sentido aos movimentos pessoais e coletivos.

Os conteúdos dos movimentos e a vida dos trabalhadores, inclusive de setores e profissões sobre os quais nunca ouvimos falar, não costumam ser objeto de noticiários. Desconhecemos como está sendo privatizada hoje a universidade pública e, dentro dela, a saúde pública; desconhecemos as políticas de todos os setores que movem e definem as nossas formas de vida e os seus impactos financeiros, físicos, afetivos, sociais, naturais, mas sabemos que no reino do capital as políticas são subordinadas à voracidade do mercado e a interesses produzidos como soberanos. Como se dá o processo de enriquecimento de alguns? Que efeitos produz esse enriquecimento em nossa existência? Estes, entre tantos outros, são conteúdos que parecem distantes, inatingíveis, embora definam os modos de vida, por terem poder de domínio, no dizer de Foucault (2005). Por oposição a uma vida pautada em palavras de ordem, em verdades essencializadas, Foucault (2003) insistia em afirmar que sua preocupação era "... analisar a relação que existe entre um conjunto de técnicas de poder e de formas...." (p. 319), o "jogo estratégico" (Foucault, 2006, p. 284), dada a necessidade de conhecermos as práticas e, por meio delas, a "racionalidade ou a regularidade que organiza o que os homens fazem" (Castro, 2004/2009, p. 338).

Quando apresentados os efeitos de alguma política não sabemos como se constituíram as práticas, os jogos de interesses, os procedimentos adotados. $O$ que chega ao grande público, àqueles que não têm intimidade com as relações apresentadas, são cenas polarizadas que vão da idealização à devastação, sem entendermos as lógicas que as fundamentam e os mecanismos por meio dos quais são executadas. Temos que decidir ou nos posicionarmos sobre a privatização ou não de um serviço, mas de fato não conhecemos as minúcias da relação em questão. O bom e o mau, o positivo e o negativo, nos atravessam na condição de rótulos absolutos que recaem sobre pessoas em sua singularidade, prescindindo do detalhamento das relações. A vida é conduzida por ameaças e sentenças. Cada vez mais nos sentimos inseguros. Não entender o que ocorre, o porquê dos acontecimentos, o que fazer ante eles, o porquê algumas práticas são definidas como crime, potencializa a incerteza. Ante a falta de conhecimento de relações sobre as quais somos convocados a nos posicionar - pela ameaça de que tais relações recairão sobre as nossas vidas e as de nossos herdeiros apresenta-se como única possibilidade escolher alguém que tome as decisões por todos. A insistência na idoneidade moral das pessoas como única saída para transformar as situações indesejadas é uma técnica de governo da democracia burguesa representativa que nos afasta das análises da racionalidade que faz funcionar as estratégias de segurança.

O julgamento moral tem contribuído para que a busca por análises e a participação nos processos institucionais se desloquem para a escolha de pessoas especializadas, sabedoras dos temas em questão, que substituirão a necessidade de entender temas e relações que definem as nossas vidas e decidirão por todos. Pareceria que só alguém idôneo reverteria o indesejado. As pessoas se tornam o ponto de tensão. Antes de pensar para entender as relações cabe confiar em alguém. $O$ medo ao outro é um importante mecanismo de controle.

A produção da insegurança como questão maior é bordada cuidadosamente, apagando do nosso espectro analítico e afetivo as decisões em relação a todos os campos que compõem a existência coletiva. A vida flui por meio de julgamentos e lutamos por encontrar cada vez melhores e maiores meios de bem julgar, acreditando estar assim construindo outras relações. No dizer "eu não gosto de política" apresenta-se uma concepção autocrática da vida, subordinada às decisões de outrem a respeito das formas de regulação. O problema coletivo passa a ser a insegurança, tornando 
todas as áreas que definem as nossas formas de vida - inclusive as relações que nos dão insegurança - distantes, difíceis, incompreensíveis e, sobretudo, sujeitas à idoneidade moral dos que têm capacidade e conhecimentos para dedicar-se a elas. É produzida a ideia que a segurança vem de alguém que sabe o que tem que fazer e tem pulso para agir. Uma questão moral e não de pensamento e mobilização coletivos; uma demanda por produção de serviços que deem segurança.

De acordo com este raciocínio todos constituímos o campo de possibilidades para garantir a segurança, se conduzidos por certa moral, que justifica estratégias que cada um pode acionar. A partir de Foucault (2012c) podemos pensar que, independentemente do que motiva a criação de certas estratégias, uma vez instituídas as lógicas que justificam a sua existência, todos as fazemos funcionar, sem pensar no longo espectro dos efeitos que produzem. Em particular podemos pensar na lógica penal que leva a que em todas as áreas sejam criadas mais normas restritivas e punitivas, mesmo quando a sua enunciação e a execução penal apresentem resultados questionáveis, como ocorre com a escola que com todas as suas regras esquadrinhadoras que vão da cor do tênis aos resultados das provas - cada vez se queixa mais da insubordinação estudantil. No mesmo sentido podemos referir a prisão que, embora idealizada como lugar da regeneração, é confirmada, historicamente, como lugar da arbitrariedade e da brutalidade. Mesmo assim, pedimos todos os dias mais grades e mais encarceramentos, como se pudéssemos esconder ou eliminar tudo aquilo que tememos. Antes, temos visto serem alimentadas as práticas instituídas como de insegurança, necessárias para fazer funcionar as máquinas de controle. São práticas que recaem nos princípios mais caros ao liberalismo, qual sejam, cidadania e liberdade, pois que convocam a participação em favor da segurança, uma vez entendida esta como questão maior e coletiva: "não há alguém ou um grupo que seja titular dessa estratégia, mas, a partir de efeitos diferentes dos fins primeiros, e da possibilidade de utilização desses efeitos, constrói-se certo número de estratégias" (Foucault, 2012c, p. 284).

\section{CIDADANIA E LIBERDADE}

Os maiores argumentos no reclamo pela insegurança têm sido a liberdade a que todos têm direito, de acordo com o estatuto jurídico liberal que nos outorga a condição cidadã. $O$ direito à cidadania é produzido como terreno da segurança e esta é entendida como proteção física. Os chamados tempos modernos têm no conceito de liberdade a sua centralidade, institucionalizada por mecanismos jurídicos em nome da proteção. Liberdade passa a ser um conceito associado ao de controle e ambos têm seu fundamento na segurança, apenas possível se produzida a insegurança. Uma relação segundo a qual a insegurança convoca a segurança e esta a justiça com os aparelhos que Ihe subsidiam.

A liberdade é constituinte das relações de poder e a segurança um dispositivo sem o qual ela inexiste: liberdade e controle são noções articuladas na construção da cidadania e esta o objeto central da sociedade moderna, em sua exaltação da condição humana. Os direitos humanos, a formação humana, a qualidade humana, o humano, em suma, como condição superior, é essencializado ao ser definido por leis e convocar a justiça com suas estratégias de controle para ser instaurado. A definição legal é uma forma de determinar por antecipação o que é possível e o que é interditado. Interessa, pois, pensar as estratégias de controle que definem no contemporâneo a chamada formação ou condição cidadã e, nela, a liberdade, entendendo-a como uma produção subjetiva que convoca o controle biopolítico, exercido com práticas que vão da sedução à militarização. São estas práticas que deixam claro quem é considerado humano e, portanto, portador da condição cidadã.

A partir das referências liberais, "o contrato social emerge como uma forma de naturalizar a condição de cidadania ou seja, a relação jurídica entre 'iguais'” (Scheinvar, 2009, p. 91), fazendo crer desnecessária qualquer discussão, sob o entendimento que uma determinação legal contém a força da obediência. Como todo princípio universal, a cidadania é um corte definido historicamente e a não condição cidadã ou a impossibilidade de ser contemplado por relações entendidas como de cidadania está longe de ser um erro na condução governamental ou um desvio do que esta deveria ser. As práticas denunciadas como impeditivas à 
condição cidadã não falam de omissões e erros, mas da afirmação do sentido que esta tem.

Cidadania, embora uma relação juridicamente estabelecida, não é uma relação passiva, nem vertical, mas produtora de formas de subjetividades; de práticas que se cristalizam, que intervêm e expressam micropoderes. Os agenciamentos coletivos hão de ser lidos não pelos ideais proclamados - como no caso da "participação cidadã"- mas através das práticas produzidas que, em sua leitura múltipla, tornam visíveis rupturas nos modelos totalizantes (Scheinvar, 2009, pp. 95-96).

Como uma produção subjetiva, a cidadania é uma produção, portanto, atravessada por deslocamentos que escapam à intenção totalizadora de uma categoria que se propõe a sedução, o ordenamento e a mobilização em favor de uma certa ordem articulada pelo desejo penal de punição e vingança. São precisamente a cidadania e a liberdade que justificam a demanda por segurança e, pela segurança, mata-se.

Toda forma de coação é justificada quando defendida a formação cidadã, condicionando as possibilidades de existência à soberania da norma. A lógica penal implementada pelo Poder Judiciário articula as relações cotidianas. Nesse movimento conceitos como o de segurança, por exemplo, orientam tanto a noção de cidadania quanto a de liberdade, acoplando e capturando ambos em uma lógica que demanda coação em qualquer de suas manifestações, conforme experimentou-se no Rio de Janeiro a partir de 2011, com a aclamação da militarização dos bairros pobres, sobretudo das favelas, chamando-a de pacificação.

As leis, antes de nos protegerem, definem o que nos ameaça. A produção da ameaça ou a definição de um acontecimento como delito também produz o responsável pela ameaça ou o delinqüente, na condição de inimigos sociais, convocando a proteção. Amparada na proteção contra eles - os inimigos sociais ou delinquentes - as estratégias de segurança vão sendo criadas. A corporificação da situação de insegurança, a individualização das relações, faz acontecer a produção de uma verdade e, como tal, dispensa a análise de contextos, lógicas, interesses ou de qualquer atravessamento a ela implicada. Opera-se um simplismo apoiado na construção de verdades. Como explica Foucault (2012a, p. 134): “A lei antidepredação permite à polícia fabricar, no local, um 'delito' e um 'delinquente', sobre os quais procedimentos de flagrante delito decalcará o selo de uma verdade sem discussão". A lei é o impedimento nem tanto ao ato, mas sobretudo ao pensamento sobre o ato. A vida conduzida por normas obstaculiza as análises e afirma o juízo como técnica de governo. Esta a lógica que pauta não só o procedimento jurídico, mas o próprio olhar sob os atos ilegais, como vemos suceder com a emissão das notícias que informam ou, mais que isto, produzem os acontecimentos forjados como atentados à cidadania e à liberdade.

Sob esta lógica a lei que instala a condição cidadã torna-se um elemento fundamental à organização social, articulada pela produção do cidadão governado na modernidade por meio dos dispositivos de disciplina e de segurança. São estes, de acordo com Foucault (2008), elementos que forjam o novo Homem, o ser livre do liberalismo, o ser da lei, da norma, o cidadão.

No mundo moderno, a cidadania é produzida como uma verdade; uma condição libertária de existência por garantir a igualdade jurídica. Ancorada na lei a condição cidadã é atravessada por uma lógica segundo a qual da capacidade de cada indivíduo depende fazer valer o que a lei já Ihe concedeu. Em uma leitura legalista, apenas um comportamento desviante impediria uma vida com cidadania, ou seja, com acesso aos direitos. Tal pensamento tem por base a ideia que 0 desvio do caminho cidadão provém daquele que não respeita os direitos do outro, seja pelo embate pessoal, seja pelo que comumente tem se chamado de imoralidade, como acontece com o desvio dos fundos públicos. Insiste-se em que o mau comportamento de cada pessoa é o responsável pelo insucesso da cidadania. As produções subjetivas e os projetos políticos que conduzem as formas de vida e as decisões coletivas não são colocados em análise. O comportamento das pessoas, como usuários ou como gestores, bem como os das famílias, é o que se destaca quando uma relação social é referida: temos bons e maus professores, presidentes, estudantes, técnicos, famílias, mas não colocamos em análise as produções subjetivas, as lógicas que nos constituem. Pareceria que isto seria algo da ordem íntima, próprio de um atendimento pessoal de psicologia, e não uma questão de interesses, perspectivas políticas, de uma racionalidade que nos constitui. Os modos coletivos por meio dos 
quais operamos são abordados como efeitos da somatória de individualidades e não como a articulação das lógicas que nos constituem, que na composição de grupos singulares fogem dos determinismos.

Assim, temos a população infanto-juvenil que no Brasil de hoje em altíssimo percentual tem acesso à escola, mas não necessariamente a reconhece como um espaço próprio e sim de coação. Nela estão muitos estudantes e trabalhadores desgostosos em suas experiências disciplinares (não só os pobres), mas os discursos (nos meios de comunicação, nas análises profissionais, nas rodas de conversa) insistem nos modos de existência particulares como definidores de quem são as pessoas adequadas para tal lugar. Mostra disso é a divulgação de experiências de sucesso escolar (geralmente apoiadas em resultados de provas institucionais) como fruto do empenho glorioso de uma professora ou de um professor, dotados de alguma qualidade heróica ou de um dom natural, mas sobretudo de uma vontade e determinação pessoal acima das adversidades. A política de educação, em si, bem como as perspectivas pedagógicas com as que se trabalha, não são objetos de análise.

Criam-se algumas verdades que eximem o exercício do pensamento. Talvez seja este o sentido que prevaleça em muitas das reuniões coletivas, convertendo-as em tediosos espaços de brigas pessoais. Pessoas que trabalham no mesmo espaço, com as mesmas questões, não encontram sentido na reunião coletiva, na conversa, na análise, na busca dos procedimentos que produzem situações de desgosto. O coletivo adquire um formato quantitativo, sem uma densidade política. De forma fragmentada diferentes setores que compõem uma relação são colocados em posições afastadas ou até opostas, demandados por uma prática que, quanto mais individualizada, mais competente é considerada, sob o entendimento que se bem feito um trabalho, trará bons resultados e não será necessário que outras equipes ou segmentos interfiram.

As ciências têm contribuído com este caminho. Estudos do campo da medicalização (Marafón, 2013) têm mostrado como eles operam sob a mesma lógica judiciária sentenciando e adotando a prescrição médica como uma verdade, a qual, como tal, tem que ser obedecida por adesão ou por coação. Ir a um serviço de saúde, fazer um tratamento, passou a ser condição para que algumas pessoas possam estar na escola, por exemplo.

Palavras de ordem que substituem análises são consumidas trazendo tranquilidade por oferecer uma resposta, mas também trazem intranquilidade por não tornarem explícito como foi construída tal resposta ou, mais bem, como foram construídas as relações explicadas por meio de verdadeiras sentenças: "Não há segurança na escola", insistem em dizer os relatos midiáticos, reclamando do comportamento das pessoas e convocando o que passou a ser chamado de segurança: a polícia. "Vândalos ocupam as manifestações", destacam os meios de comunicação ao noticiarem um acontecimento-protesto, buscando inibir a adesão a tais movimentos usando à sua maneira o terrorismo, ou seja, um instrumento de disputa de força política. Não são discutidas as relações que atravessam e constituem a vida, apenas são exaltados comportamentos idealizados. Tais enunciações com caráter de verdade tornam-se algo que é entendido como proteção à vida. Com um pensamento esquemático, comportamental,

\begin{abstract}
defender a sociedade se torna um princípio funcional comum à polícia, aos procuradores, aos magistrados instrutores e aos juízes. Os controles mútuos, os balanços, as indispensáveis divergências entre os diferentes elementos da instituição se esfumam em benefício de uma continuidade aceita, reivindicada (Foucault, 2012a, p. 134).
\end{abstract}

Com uma lógica simplista, porque abstraída da densidade das relações políticas, apresentase uma fórmula que estabelece que a cidadania é um contrato jurídico que supõe uma certa estrutura do Estado e um certo comportamento das pessoas, ou seja, uma referência idealizada para a superação das diferenças, entendendo serem estas as que definem os conflitos. Com o mesmo simplismo são entendidos os mecanismos para garantir a cidadania, igualando - como diz Foucault no trecho recém citado - os procedimentos, o que significa liberdade total às práticas entendidas como de defesa cidadã. A intervenção, seja como for e a qualquer preço, é produzida como uma necessidade urgente $\mathrm{e}$ prioritária, para que salvemos a condição cidadã, fechando fileiras entre todos aqueles investidos institucionalmente da tarefa de cuidar da 
cidadania, seja na condição de polícia, juiz, pedagogo, médico ou professor, ou de cidadão, já que tal condição nos coloca no dever de vigiar o outro.

O fundamento para agir é dado pela condição jurídica da cidadania, base de acesso a certo modo de vida outorgado pela lei, e fazer valer a lei é a garantia cidadã. O policiamento é um elemento central à cidadania, assim, toda ação que se diz necessária a ela é apoiada na lógica do direito, portanto, na ordem jurídica. A cidadania convoca as práticas jurídicas e incita à judicialização da vida.

\section{A JUDICIALIZAÇÃO COMO INCENTIVO À INSEGURANÇA}

Pautar a vida em normas jurídicas, judicializar as relações, é uma perspectiva que incentiva a insegurança como condição para falar em segurança. Foucault (1973/2008) define a segurança como um dispositivo que age "sobre o conjunto da população" (p.16) simultaneamente e apoiando-se na lei e na disciplina: "A segurança é uma certa maneira de acrescentar, de fazer funcionar, além dos mecanismos propriamente de segurança, as velhas estruturas da lei e da disciplina" (p.14). Para Foucault a segurança é uma forma de controle, cuja tecnologia é acionada pela incitação ao perigo. Um perigo não só retórico, mas declarado por lei, por um dos instrumentos que fazem a máquina de controle funcionar, constrói os inimigos materializando o medo e convocando a máquina judiciária. $O$ medo ao outro justifica o acionamento das tecnologias de segurança sob a crença de estar-se defendendo a população, tendendo nem tanto “... à vitória sobre os adversários políticos, mas à eliminação do perigo..." (1973/2002, p. 306). O perigo, o perigoso, é o motor do controle e recai sobre a população.

Foucault (2008) diz que à diferença da disciplina, que recorta a multiplicidade e nesse movimento a individualiza, a segurança opera sobre a população enquanto multiplicidade. As tecnologias de segurança regulam o que é definido como perigo e para inibi-lo atravessam a todos, mesmo que de formas diferentes, de acordo com os setores a que são orientadas as estratégias. Formas diferentes para discursos generalizados. A produção subjetiva em torno do perigo é fundamental para afirmar a condição de liberdade e a condição cidadã. Ante tal produção
Foucault (1973/2008) se pergunta se “... em nossas sociedades a economia geral de poder está se tornando da ordem da segurança?" (p. 15). A partir de sua questão podemos indagar: se a referência jurídico-política do liberalismo é a constituição do cidadão, e este é um ser livre, cuja liberdade depende da segurança, está nesta, então, a centralidade das relações sociais liberais? Nesse mesmo sentido podemos ampliar tal problematização com a seguinte questão: se a gestão política se dá por meio de estratégias de governo, serão as estratégias de segurança o eixo da governabilidade?

Orientar as relações de poder a partir de relações de segurança implica pensar o que é produzido como insegurança e como esta é produzida, ou seja, quais as estratégias de produção de insegurança, para agir em nome da segurança. Desta perspectiva questiona Foucault (2008) se "sob o nome de sociedade de segurança ... há efetivamente uma economia geral de poder que ... seja dominada pela tecnologia de segurança" (p. 15).

A segurança, produzida como uma necessidade do que é chamado humano, passa a ser uma área a mais do mercado, no mundo do capital: alimenta-se uma indústria de insegurança e um espaço de lucro. Vende-se segurança como condição para viver. Ela toma conta dos afetos ao operar dizendo fazer justiça, pois trata-se de "... uma justiça que se dá como tarefa velar sobre uma população, mais do que respeitar os sujeitos de direito" (Foucault, 2012b, p.102). A segurança justifica qualquer ação pois, em termos de Foucault (2012b), "doravante, a segurança está acima das leis” (p.102). Ou seja, a chamada segurança justifica qualquer ação, por cruel, radical e violenta que seja. Além de ser uma estratégia subjetiva, a produção da insegurança é uma estratégia financeira cada vez mais rentável.

A pobreza é uma histórica captadora de recursos e quanto mais alarmismo mais fluxo de capital vemos circular em torno de um mercado tanto de políticas públicas como de grupos privados na forma de empresas, projetos, programas, interferindo nos ajustes econômicos. A segurança é mais um espaço de rentabilidade. Não por acaso a discussão sobre a redução da idade penal e a necessidade de maior encarceramento tem sido alimentada em muitos países, simultaneamente à discussão internacional sobre a privatização do cárcere. Interessa prender em grande escala, como exige 
a reprodução ampliada do capital, o que só é possível alimentando a lógica penal como lógica de vida.

A infração penal conduz não só as notícias, como as nossas relações mais íntimas: a educação de filhos, o relacionamento com idosos, as relações conjugais, as relações profissionais, todas as esferas da vida cotidiana passaram a se pautar em determinações legais que definem padrões. Agora não se discute mais como querem viver as pessoas, como distribuir os seus bens, como conduzir as relações com seus filhos e cônjuges, mas procura-se na lei o que pode. $O$ pensamento e o desejo são abolidos do espectro íntimo. Passam a ser dimensões públicas, mas não no sentido dos atravessamentos afetivos e morais que nos constituem, e sim por imposição de normas às que somos submetidos por ameaça e coação. $O$ desvio do padrão é delito e a regeneração uma tarefa de enorme sedução, acreditando na humanização.

Exemplos cotidianos em salas de aula, em conselhos tutelares, nos aparelhos da justiça, nos centros de assistência social, mostram como cabe ao profissional explicar e exigir como devem viver as pessoas: para garantir uma renda, para poder matricular um filho na escola, para não ter os seus filhos retirados de sua família e colocados na fila de adoção, para ter acesso a um serviço de saúde, para sair ou ficar sob certas condições na prisão e em suas formas heteronímicas... Mas agora não só a norma moral pauta os trabalhadores, como há séculos acontece. A presença da norma legal ostensiva que alguns discursos entendem como amparo e orientação ao trabalhador trouxe também uma dureza às relações profissionais, pois que recai não só nos usuários, mas também nos trabalhadores, cujas cabeças - igual que a dos usuários - ficam na mira das leis e dos aparelhos de justiça que os ameaçam, retirandoIhes a possibilidade de pensar, de construir estratégias a partir de referências distintas daquelas pré-estabelecidas. Uma vida ameaçada pela lei!

\section{CONDECORAÇÕES ACADÊMICAS PARA AS PRÁTICAS DE SEGURANÇA}

Chama a atenção a forma como estas demandas por obediência legal chegam à universidade e também são produzidas por ela. $O$ interesse por pesquisas e intervenções associadas ao campo da infração penal aumentam todos os dias: escolas em prisão, estudar prisões, fazer boas prisões, capacitar a polícia, cursos universitários para carcereiros... A crença na prisão, a crença na regeneração, a crença no comportamentalismo, pautadas pela lógica judiciária invade as salas de aula de forma dissociada das práticas concretas nas prisões, nas ruas, nos movimentos populares, em todos os espaços em que as estruturas coativas operam.

Estudar os aparelhos coercitivos $\mathrm{e}$ as técnicas de controle tem sido um exercício abstraído da forma como estes são executados. Há um olhar condescendente e esperançoso quando não mercantil - para com aqueles que operam diretamente as máquinas coativas, sem associá-los às formas subjetivas que as fazem funcionar; sem associar a produção subjetiva dos operadores das estratégias de segurança dentre eles as equipes das universidades que formam profissionais que atuam diretamente nos aparelhos de repressão - ao seu assujeitamento às técnicas de governamentalidade (Revel, 2011, p. 144).

As relações de poder para Foucault não estão centradas em uma figura central, nem funcionam por dicotomia entre estas e os súditos, portanto, não operam, como diz Revel (2011), pela "confrontação entre o poder e a liberdade" (p. 121), já que de acordo com a autora,

\begin{abstract}
é exatamente tornando-os indissociáveis que Foucault pode identificar no poder um papel não somente repressivo, mas também produtivo (de consequências, de verdade, de subjetividades, de lutas), e que ele pode, inversamente, enraizar os fenômenos de resistência no próprio interior do poder, que eles procuram contestar, e não num improvável “exterior” (Revel, 2011, p. 121).
\end{abstract}

Pensar no Estado e seus aparelhos como um bloco distancia-se da perspectiva microfísica que apresentam os estudos de Foucault, de acordo com os quais o poder circula de forma capilar, sorrateira, produzindo subjetivações múltiplas que definem formas diversas de assujeitamento. É desta perspectiva que considero importante pensar as práticas da universidade em relação às corporações que constituem os aparelhos de segurança, já que se não entendido o poder como uma entidade externa interessa colocar em análise os 
assujeitamentos produzidos que dão potência aos aparelhos de repressão por meio da adesão profissional. Na entrevista publicada sob o nome "O sujeito e o poder" (Foucault, 1982/2010), Foucault procura frisar o seu interesse não no sujeito, mas nos modos de subjetivação que dão lugar a práticas de assujeitamento:

Eu gostaria de dizer, antes de mais nada, qual foi o objetivo do meu trabalho nos últimos 20 anos. Não foi analisar o fenômeno do poder nem elaborar os fundamentos de tal análise.

Meu objetivo, ao contrário, foi criar uma história dos diferentes modos pelos quais, em nossa cultura, os seres humanos tornaram-se sujeitos (p.273).

Cursos são oferecidos, pesquisas realizadas, horrores são contemporizados em linguagem acadêmica e a legitimidade que a universidade vai conferindo a tais práticas de repressão passa desapercebida não pelos que estão fora de seus muros, que se fortalecem com tal aliança, mas por nós mesmos. O interesse em sala de aula pelos movimentos sociais e pelas lutas por transformar as lógicas de vida cede para interesses por fazer a máquina de controle funcionar, exaltando o reino da submissão à ordem instituída, à disciplina, ao conformismo frente aos limites do mercado. Uma discussão em torno do mercado e não de enfrentamento a ele. Há concessões éticas justificadas pelo discurso do ensinamento de conteúdos históricos e éticos. Prevalece a ideia do poder acima das pessoas e destas como vítimas de estruturas que as sobrepassam. A capilaridade das relações de assujeitamento escapa à percepção daqueles que se juntam às estruturas de segurança engrossando-as e condecorandoas com certificados acadêmicos.

As estratégias de segurança, com todos os seus aparelhos (físicos e humanos) se encontram com a crença no mercado como regenerador, que finalmente irá gerir com idoneidade e competência a defesa da lei. $O$ financiamento de projetos, a compra de serviços públicos e privados, o equipamento ostensivo na vida cotidiana são amparados pela idoneidade moral daqueles que trabalham, prescindindo da discussão sobre 0 que chamamos de insegurança e as formas como esta se produz. Condomínios, escolas, postos de saúde, universidades tornam evidente a racionalidade que nos faz prisioneiros da lógica penal, que demanda por aparelhos de justiça e judicializa a vida. Uma vida sustentada no incentivo às tecnologias de segurança, que padronizam e serializam a existência.

A insegurança como estratégia de controle, fundamental ao funcionamento da sociedade contemporânea, converteu-se em mais uma indústria de reprodução do capital que coloca nas prateleiras do mercado a segurança em todas as suas apresentações. Um mercado que incentiva práticas jurídicas, a judicialização da vida, aprisionando a potência do humano no enquadramento, na ameaça, no medo. E recusar o medo como inspiração da vida é um desafio, pois como poeticamente nos orienta Deleuze (1990, p. 218):

Acreditar no mundo é o que mais nos falta; nós perdemos completamente o mundo, nos desposaram dele. Acreditar no mundo significa principalmente suscitar acontecimentos, mesmo que pequenos, que escapem ao controle....

\section{REFERÊNCIAS}

Calvino, I. (1990). As cidades invisíveis. (D. Mainardi, Trad.). São Paulo: Companhia das Letras. (Original publicado em 1973).

Castro, E. (2009). Vocabulário de Foucault - Um percurso pelos seus temas, conceitos e autores. (I. Xavier, Trad.). Belo Horizonte: Autêntica. (Original publicado em 2004).

Deleuze, G. (1992). Conversações. (P. Pál Pelbart, Trad.). São Paulo: 34.

Foucault, M. (2002). Em Defesa da Sociedade. São Paulo: Martins Fontes. (Original publicado em 1973).

Foucault, M. (2003). Foucault estuda a razão de Estado In M. B. Motta. (Org.), Ditos e escritos IV- Estratégia Poder Saber (pp. 317-323) Rio de Janeiro: Forense Universitária.

Foucault, M. (2005). O que são as luzes? In M. B. Motta. (Org.), Ditos e escritos II - Arqueologia das Ciências e História dos Sistemas de Pensamento (pp. 335-352). Rio de Janeiro: Forense Universitária.

Foucault, M. (2006). A ética do cuidado de si como prática da liberdade. In M. B. Motta. (Org.). Ditos e Escritos V-Ética, Sexualidade, Política (pp. 264-287). Rio de Janeiro: Forense Universitária.

Foucault, M. (2008). Segurança, Território, População. São Paulo: Martins Fontes. (Original publicado em 1973).

Foucault, M. (2010). O sujeito e o poder. In H. L. Dreyfus \& P. Rabrinow. Michel Foucault: uma trajetória filosófica. Para além do estruturalismo e da hermenêutica (pp. 229-249). (V. P. Carrero \& G. Carneiro, Trads.). Rio de Janeiro: Forense Universitária. (Original publicado em 1982). 
Foucault, M. (2012a). A estratégia do contorno. In M. B. Motta. (Org.), Ditos e escritos VIII - Segurança, Penalidade e Prisão (pp. 133-136). Rio de Janeiro: Forense Universitária.

Foucault, M. (2012b). Michel Foucault: doravante a segurança está acima das leis. In M. B. Motta. (Org.), Ditos e escritos VIII- Segurança, Penalidade e Prisão (pp.101-103). Rio de Janeiro: Forense Universitária.

Foucault, M. (2012c). O que chamamos punir? In M. B. Motta. (Org.), Ditos e escritos VIII - Segurança, Penalidade e Prisão (pp. 280-291). Rio de Janeiro: Forense Universitária.

Marafón, G. (2013). Vida em judicialização: o efeito bullying como analisador. Tese de Doutorado, Programa de PósGraduação em Psicologia, Universidade Federal Fluminense, Niterói, RJ.
Revel, J. (2011). Dicionário Foucault. Rio de Janeiro, Forense Universitária. (Original publicado em 2007).

Scheinvar, E. (2009). O feitiço da política pública. Escola, sociedade civil e direitos da criança e do adolescente. Rio de Janeiro: Lamparina/Faperj.

Recebido em 10/11/2013 Aceito em 04/10/2014

Estela Scheinvar: doutora em Educação, professora do Departamento de Educação e do Programa de Pós-graduação em Políticas Públicas e Formação Humana na Faculdade de Formação de Professores de São Gonçalo da Universidade do Estado do Rio de Janeiro, socióloga do Serviço de Psicologia Aplicada da Universidade Federal Fluminense.. 